\title{
Temporal and Spatial Evolution of Climate Comfort and Population Exposure in Guangdong Province in the Last Half Century
}

\author{
Ziqiang Ye $^{1}$, Song Song ${ }^{1,2^{*}}$, Runfei Zhong ${ }^{1}$ \\ 1School of Geographical Sciences, Guangzhou University, 510006, Guangzhou, China \\ 2Southern Marine Science and Engineering Guangdong Laboratory (Guangzhou), 511458, \\ Guangzhou, China
}

\begin{abstract}
Regional Climatic Comfort Index (CCI) deteriorated significantly due to the climate change and anthropogenic interference. Knowledge regarding the long-term temporal dynamics of CCI in typical regions should be strengthened. In this study, we analyze the temporal and spatial evolution of CCI from 1969 to 2018 in Guangdong Province, based on meteorological indicators, including heat, humidity, wind and cloth loading etc.. Additionally, the population exposure to climate unconformity was examined since 1990 with the help of population data. Our study found that: (1) the warming and humidifying of the summer climate served as the main driving force for the continuous deterioration of CCI, with the comfortable days decreased by $1.06 \mathrm{~d} / 10 \mathrm{a}$ and the extremely muggy days increased by $2.83 \mathrm{~d} / 10 \mathrm{a}$; (2) spatially, the lowest climate comfortability concentrated in southwestern Guangdong with more than 50 uncomfortable days each year, while the climate comfortability in northeastern Guangdong tends to deteriorated whit higher rate, which can reach as high as $6 \mathrm{~d} / 10 \mathrm{a}$; (3) in summer, the population exposure to uncomfortable climate highly centralized in the Pearl River Delta, Shantou, Jieyang, and the surrounding areas, and both area and population exposure showed increasing trends. Particularly, Shenzhen held the highest growth rate of population exposure with an increase rate of 2.94 million/10a; (4) although the discomfort distribution and deterioration rate vary across the province, the spatial heterogeneity of comfortability is diminishing in Guangdong Province. This study will provide scientific reference for regional urban planning, thermal environment improvement, local resident health risk analysis, and key strategy implementation, etc.
\end{abstract}

Key words: climate comfort index; temperature-humidity index; wind-effect index; clothing index; population exposure 


\section{Introduction}

Climatic Comfort Index (CCI) is a biometeorological indicator evaluating the comfort of human beings in different climatic conditions from the perspective of meteorology, stemmed from the principle of heat exchange between the human body and the near-Earth atmosphere(Feng et al., 2021). Under the background of global change, more frequent climate extremes, including heat waves, rainstorms, and tropical storms with higher intensity have been witnessed all over the world(Fischer et al., 2021; Thiery et al., 2021), posing higher burden on human regulatory capability, threatening the public's lives and health and at the same time leading to significant economic losses(Batibeniz et al., 2020; Forzieri et al., 2018; Hong et al., 2019). As a comprehensive denotation of climatic conditions, including temperature, humidity, wind, etc., CCI alteration can negatively impact on human health and socioeconomic life severely once the threshold got overran(Zhou et al., 2018). It's particularly significant to discuss the influence of climate change on human body's awareness in the perspective of CCI (Odnoletkova and Patzek, 2021). Moreover, conducting long-term CCI evaluation research with daily ground monitoring data for one thing strengthen the understanding of climate change and its influences, and for another provide scientific guidance for the regulation of human settlement assessment, urban and rural planning, climate event response, and the corresponding adaptive strategies (Aminipouri et al., 2019; Dino and Meral Akgül, 2019; Summa et al., 2020).

Extensive CCI research has been carried out domestically and globally based on various CCI models (Blazejczyk et al., 2012; Cheung and Hart, 2014). Evaluations of CCI were based on simple empirical models in the early stage which developed into complex mechanism models in recent years, with the refinement of data source and the diversification of the research aims (Ma and Sun, 2009; Odnoletkova and Patzek, 2021). Since the early $20^{\text {th }}$ century, the influence of different meteorological factors on human comfort originated from Europe and the United States in early $20^{\text {th }}$ century(Barbosa et al., 2015; Kramer et al., 2017). More than 160 evaluation indices have been successively involved in climate comfort evaluation in the last few decades, including Discomfort Index (DI)(Poupkou et al., 2011), Wind Chill Index (WCI)(Roshan et al., 2010), Temperature-Humidity Index (THI)(Steadman, 1979), and Index of Cloth Loading (ICL) (Rong et al., 2017), Physiological 
Equivalent Temperature (PET) (Höppe, 1999; Y. Wu et al., 2020), Universal Thermal Climate Index (UTCI) (Blazejczyk et al., 2012; Zeng et al., 2020), Climate-Tourism/Transfer-Information Scheme (CTIS) (Li and Chi, 2014; Matzarakis, 2013), and Tourism Climate Index (TCI) (Noome and Fitchett, 2019; Scott et al., 2016). CCI research in China started relatively late, focusing on the temporal and spatial dynamic analysis of CCI stemmed from the combined mature empirical models (Chen et al., 2005; Li and Chi, 2014; Ma and Sun, 2009), with the support of geographic information system (GIS) and remote sensing data (RS) (Feng et al., 2021; F. Wu et al., 2020; Wu et al., 2019). Some scholars explored the response mechanism between CCI and geographic factors, including topography (Zhang et al., 2018), altitude (Sun and Yu, 2014), eco-community (Cai and Zhou, 2012), and land use type on the meso- and micro-scale (Yang et al., 2019), and tried to investigate their correlations with human comfort. Moreover, the applications of CCI have been expanded to tourism, economics, society, psychology, and other disciplines, attaining a series of advancements has been attained in aspects such as human comfort in residence and tourist destinations, comfort experience of tourists, and the influence of comfort on emotional management (Hayes et al., 2018; Ko et al., 2020; Stechemesser et al., 2021).

With the further warming of the global climate and intense interference of human activities (Fischer et al., 2021), regional meteorological conditions are conductive to variations and uncertainties in regional CCI, which eventually influence the human body and local social-economic environment to varying extents. The evaluation of regional CCI and research of its spatial-temporal changes lay the basis for clarifying the climate change impact and relieving the negative influence of climate deterioration. It is essential to conduct high-precise and long-sequenced research on spatialtemporal CCI patterns, particularly for metropolitan areas with a dense population and rapid economic growth.

As one of the pilot regions of China's reform and opening up, Guangdong Province has experienced a rapid concentration of the economy, population, and resources over recent decades, resulting in a non-negligible cumulative effect of climate change impact (Li et al., 2020). Under the economic and social vision where major strategies such as the Guangdong-Hong Kong-Macao Greater Bay Area and the "Belt and Road Initiative" are continuously advanced, the regional urban 
expansion and population agglomeration will continue proceed rapidly owing to the sufficient social/economic driving force. Compounding the climate background of inhomogeneous global and regional warming, Guangdong Province will face unprecedent climate and environmental challenges. Given the above considerations, Guangdong Province was taken as the research object, where the daily meteorological data of 86 meteorological stations for nearly 50 years were collected to explore the spatial-temporal dynamic of CCI, covering the temperature, humidity and clothing index. The seasonal variation and spatial pattern of population exposure to discomfort climate were analyzed based on CCI model and population growth data. This paper aims to provide a scientific and theoretical reference for regional urban planning, the thermal environment improvement of human settlements, and advancement of major strategies.

2. Overview of the research area and research methods

2.1 Research area and data sources

Guangdong Province is located in the southeastern coastal area of China across 109.65-117.32 E and $20.22-25.52^{\circ} \mathrm{N}$, bordering the South China Sea, and it has a total land area of $178,500 \mathrm{hm}^{2}$. Dominated by a subtropical monsoon climate with hot and rainy summers and cool and dry winters, it is one of the regions in China with abundant light, heat, and water resources. The weather and climate are of high seasonal and interannual variation, with frequent incidences of natural disasters, such as tropical cyclones, thunderstorm, drought, and heat/cold waves. 


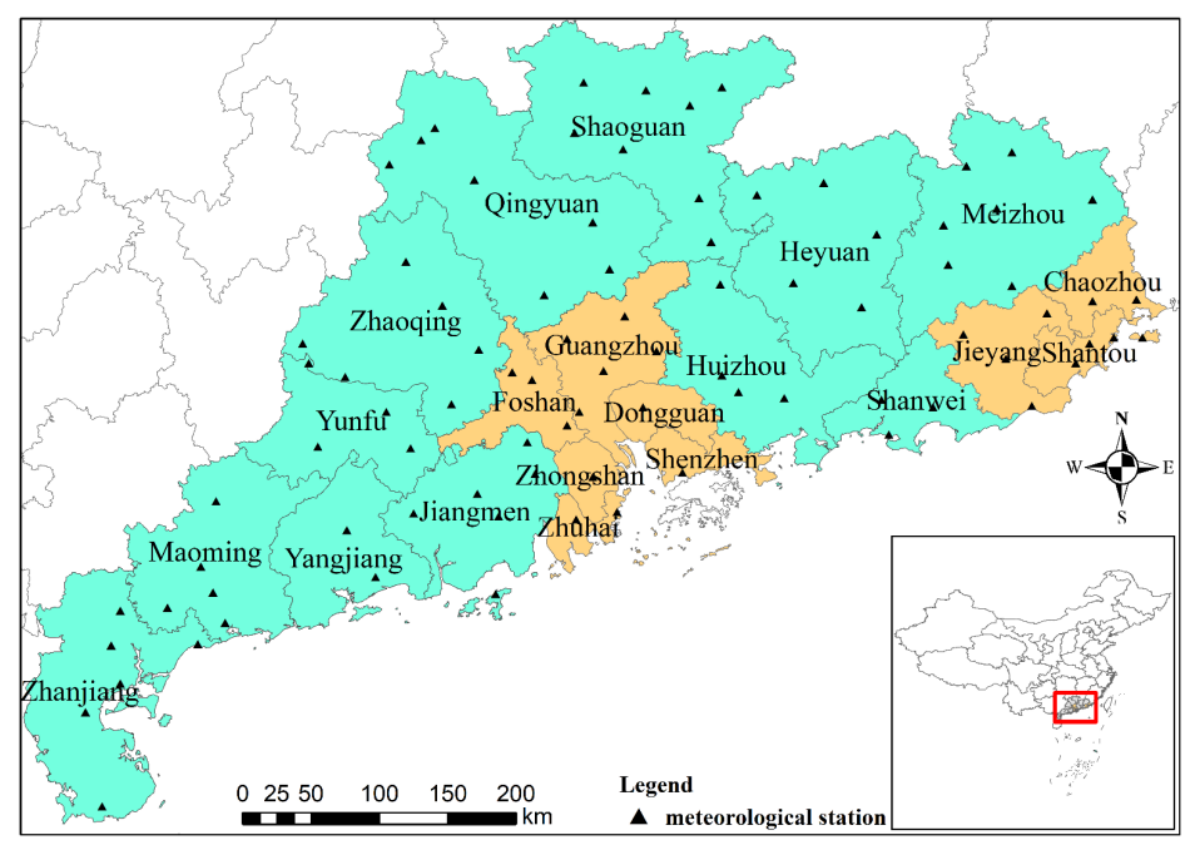

Figure 1: Location of the study region and meteorological station

In this paper, with the observation data of 86 meteorological stations (Figure 1) in Guangdong Province from 1969 to 2018, the modeling and evaluation of CCI were conducted based on daily average temperature, relative humidity, sunshine hours, and other meteorological elements. Furthermore, the population spatial distribution data (gridded spatial distribution data, POP) from the Data Center for Resources and Environmental Sciences Chinese Academy of Sciences in 1990, 2000, 2010, and 2015, as well as data for the permanent resident population specified in the 1991-2019 statistical yearbook of Guangdong prefecture-level cities, were collected for the calculation and evaluation of population exposure to discomfort climates.

\subsection{Research methods and evaluation indicators}

The CCI evaluation model recommended by China's “Climate Suitability Evaluation on Human Settlement Environment" (GB/T27963-2011) mainly covers THI, WEI, and other indicators. Based on previous CCI evaluation models, ICL was combined with THI and WEI to build a integrated CCI evaluation index system(Zhang et al., 2018; Zhao and Wang, 2021). The weights of indicators were determined by classification and assignment, analytic hierarchy, and other methods. Then, a comprehensive CCI evaluation model was established to perform a thorough evaluation of regional CCI (Table 1). 
Table 1: The grading standard of THI, WEI, ICL and CCI

\begin{tabular}{|c|c|c|c|c|c|c|c|}
\hline \multicolumn{2}{|c|}{$\begin{array}{c}\text { Temperature- } \\
\text { Humidity Index (THI) }\end{array}$} & \multicolumn{2}{|c|}{$\begin{array}{l}\text { Wind Efficiency Index } \\
\text { (WEI) }\end{array}$} & \multicolumn{2}{|c|}{$\begin{array}{l}\text { Index of Cloth Loading } \\
\text { (ICL) }\end{array}$} & \multicolumn{2}{|c|}{$\begin{array}{c}\text { Climate Comfort Index (CCI) } \\
\text { Grade }\end{array}$} \\
\hline $\begin{array}{l}\text { Grade } \\
\text { value }\end{array}$ & $\begin{array}{l}\text { Human } \\
\text { feeling }\end{array}$ & Grade value & $\begin{array}{l}\text { Human } \\
\text { feeling }\end{array}$ & $\begin{array}{l}\text { Grade } \\
\text { value }\end{array}$ & Human wear & Symbols & Assignment \\
\hline$\leq 40$ & $\begin{array}{l}\text { Extremely } \\
\text { cold }\end{array}$ & $\leq-1000$ & $\begin{array}{l}\text { Extremely } \\
\text { cold wind }\end{array}$ & $\geq 2.5$ & $\begin{array}{l}\text { Down-filled or } \\
\text { fur clothes }\end{array}$ & $\begin{array}{l}\text { e. Extremely } \\
\text { uncomfortable }\end{array}$ & $\leqslant 1$ \\
\hline $40-45$ & Cold & $-1000-800$ & Cold wind & $1.8-2.5$ & $\begin{array}{l}\text { Casual clothes } \\
\text { plus coat }\end{array}$ & $\begin{array}{c}\mathrm{d} . \\
\text { Uncomfortable }\end{array}$ & $1-3$ \\
\hline $45-55$ & $\begin{array}{l}\text { Relatively } \\
\text { cold }\end{array}$ & $-800--600$ & $\begin{array}{l}\text { Relatively } \\
\text { cold wind }\end{array}$ & $1.5-1.8$ & Winter clothes & $\begin{array}{l}\text { c. Relatively } \\
\text { uncomfortable }\end{array}$ & $3-5$ \\
\hline $55-60$ & Cool & $-600--300$ & Cool wind & $1.3-1.5$ & $\begin{array}{c}\text { Spring and } \\
\text { autumn clothes }\end{array}$ & $\begin{array}{l}\text { b. Relatively } \\
\text { comfortable }\end{array}$ & $5-7$ \\
\hline $60-65$ & Refreshing & $-300--200$ & Cosy wind & $0.7-1.3$ & $\begin{array}{l}\text { Shirts and casual } \\
\text { clothes }\end{array}$ & A. Comfortable & $7-9$ \\
\hline $65-70$ & Warm & $-200--50$ & $\begin{array}{l}\text { Warm } \\
\text { wind }\end{array}$ & $0.5-0.7$ & $\begin{array}{c}\text { Light summer } \\
\text { clothes }\end{array}$ & $\begin{array}{l}\text { B. Relatively } \\
\text { comfortable }\end{array}$ & $5-7$ \\
\hline $70-75$ & Hot & $50-80$ & $\begin{array}{l}\text { Relatively } \\
\text { warm } \\
\text { wind }\end{array}$ & $0.3-0.5$ & Polo shirts & $\begin{array}{l}\text { C. Relatively } \\
\text { uncomfortable }\end{array}$ & $3-5$ \\
\hline $75-80$ & Muggy & $80-160$ & Hot wind & $0.1-0.3$ & $\begin{array}{l}\text { Tropical single- } \\
\text { layer clothes }\end{array}$ & $\begin{array}{c}\text { D. } \\
\text { Uncomfortable }\end{array}$ & $1-3$ \\
\hline$\geq 80$ & $\begin{array}{l}\text { Extremely } \\
\text { muggy }\end{array}$ & $\geq 160$ & $\begin{array}{l}\text { Extremely } \\
\text { hot wind }\end{array}$ & $\leq 0.1$ & $\begin{array}{l}\text { Light tropical } \\
\text { single-layer } \\
\text { clothes }\end{array}$ & $\begin{array}{l}\text { E. Extremely } \\
\text { uncomfortable }\end{array}$ & $\leqslant 1$ \\
\hline
\end{tabular}

The definition and calculation method of each index are detailed below:

(1) THI: A combination of temperature and humidity reflecting the heat flow between the human body and the surrounding environment(De Freitas, 1979). This is a classic index for evaluating thermal discomfort, expressed as:

$$
\mathrm{THI}=(1.8 \times \mathrm{T}+32)-0.55 \times(1-\mathrm{RH}) \times(1.8 \times \mathrm{T}-26)
$$

Where $T$ is the temperature in degrees Celsius $\left({ }^{\circ} \mathrm{C}\right)$, and $R H$ is the relative humidity.

(2) WEI: The law of human body heat loss under the constraints of wind speed and temperature, an important indicator originating from the cold environment evaluation(Wilson, 1967). WEI specifically indicates the heat exchange amount per unit area of the body surface at a skin temperature of $33{ }^{\circ} \mathrm{C}$, expressed as:

$$
\mathrm{WEI}=-(10 \times \sqrt{V}+10.45-\mathrm{V}) \times(33-\mathrm{T})+8.55 \times \mathrm{S}
$$


Where $V$ denotes the wind speed $(\mathrm{m} / \mathrm{s}), T$ represents the temperature $\left({ }^{\circ} \mathrm{C}\right)$, and $S$ is sunshine hours $(\mathrm{h} / \mathrm{d})$.

(3) ICL: Cloth loading recommendations are based on many factors, including temperature, solar radiation, human metabolism, and wind speed. Different choices of cloth loading can effectively improve or exacerbate climate discomfort(Zhao and Wang, 2021).

$$
\mathrm{ICL}=\frac{33-T}{0.155 \times H}-\frac{H+A \times R \times \cos \alpha}{H \times(0.62+19.0 \times \sqrt{V})}
$$

Where $H$ is $75 \%$ of the human body's metabolic rate (under small activity), taken as $87 \mathrm{~W} / \mathrm{m}^{2}, A$ means the human body's absorption of solar radiation, taken as $0.06, R$ is the solar constant, taken as $1367 \mathrm{~W} / \mathrm{m}^{2}$, and $\alpha$ is the solar altitude angle, taken as the average condition.

(4) CCI: A comprehensive representation of regional CCI, which is generated based on the weighted average of THI, WEI and ICL,

$$
\mathrm{CCI}=0.6 \times X_{T H I}+0.3 \times X_{W E I}+0.1 \times X_{I C L}
$$

Where $X_{T H I}, X_{W E I}$, and $X_{I C L}$ are the graded assignments of THI, WEI, and ICL, respectively, with the weight coefficients of $0.6,0.3$, and 0.1 , respectively. Specifically, the comfort level, relatively comfortable level, relatively uncomfortable level, and the discomfort level were defined by $7 \leq$ $\mathrm{CCI} \leq 9,5 \leq \mathrm{CCI}<7,3 \leq \mathrm{CCI}<5$, and $1 \leq \mathrm{CCI}<3$, respectively.

\subsection{Statistical analysis}

(1) Daily CCI was calculate based on the equations 1-4, and the monthly and annually comfort/discomfort periods were then obtained by adding up the number of comfort/discomfort days in the corresponding month or year. The monthly CCI was assigned to NULL if the missing or false measurements exceeded more than $6 \mathrm{~d}$.

(2) Linear trend estimation ${ }^{[6]}$ was applied to the analysis of the climate change trend as well as 
the he CCI and comfort/discomfort period variation.

\subsection{Analysis of population exposure}

(1) Spatial analysis of population exposure was conducted based on the summer data of the comprehensive discomfort days (SD) from 86 stations in 1990, 2000, 2010, and 2015. Spatial interpolation was performed with the Ordinary Kriging method. Then, the SD spatial-temporal distribution map of Guangdong Province was formulated, with a time resolution of 1 year and a spatial resolution of $1 \mathrm{~km}$. Herein, the exposure degree of the climate discomfort population was defined as the product of the SD corresponding to the grid point and population size.

$$
P U_{i j}=P_{i j} \times \frac{U_{i j}-\min _{i}}{\max _{i}-\min _{i}}
$$

Where $P U_{i j}$ is the population exposure of Grid $\mathrm{j}$ in the $i$-th year, $P_{i j}$ is the population size of Grid $\mathrm{j}$ in the $i$-th year, $U_{i j}$ is the SD of Grid $\mathrm{j}$ in the $i$-th year, and $\max _{i}$ and $\min _{i}$ are the maximum and minimum values of SD within 29 years, respectively.

(2) Time analysis of population exposure was carried out based on the SD data of stations during 1990-2018. The exposure of the discomfort population in every prefecture-level city was defined as the product of SD and the number of permanent residents in the city.

$$
P U_{i j}=P_{i j} \times \frac{U_{i j}-\min _{i}}{\max _{i}-\min _{i}}
$$

Where $P U_{i j}$ is the population exposure of City $\mathrm{j}$ in the $i$-th year, $P_{i j}$ is the number of permanent residents of City $\mathrm{j}$ in the $i$-th year, $U_{i j}$ is the SD of City $\mathrm{j}$ in the $i$-th year, and $\max _{i}$ and $\min _{i}$ are the maximum and minimum values of SD within 29 years, respectively.

\section{Results}

3.1Temproal evaluation of the comfortable indexes

The temporal tendency of THI, WEI and ICL in the last 50 years were shown in Figure 2. The annual average variation range of THI was $68-72$, showing a significant rising trend, and human feeling tended to be relatively hot (the relatively uncomfortable level) compared with warm feeling before (the relatively comfortable level) (Fig. 2a). The annual average of WEI fluctuated between 227-177, exhibiting an overall rising trend, more warm wind (the relatively comfortable level) were 
felt compared with comfortable wind (the comfortable level) (Fig. 2b). In terms of clothing, larger temporal fluctuations were revealed in $I C L$ compared with the other two indexes, with a value range of 0.68-0.78. A slight decreasing trend was detected in ICL, indicating less clothes was recommended over time, especially from late 1980s to the beginning of 2000 (Fig. 2c).
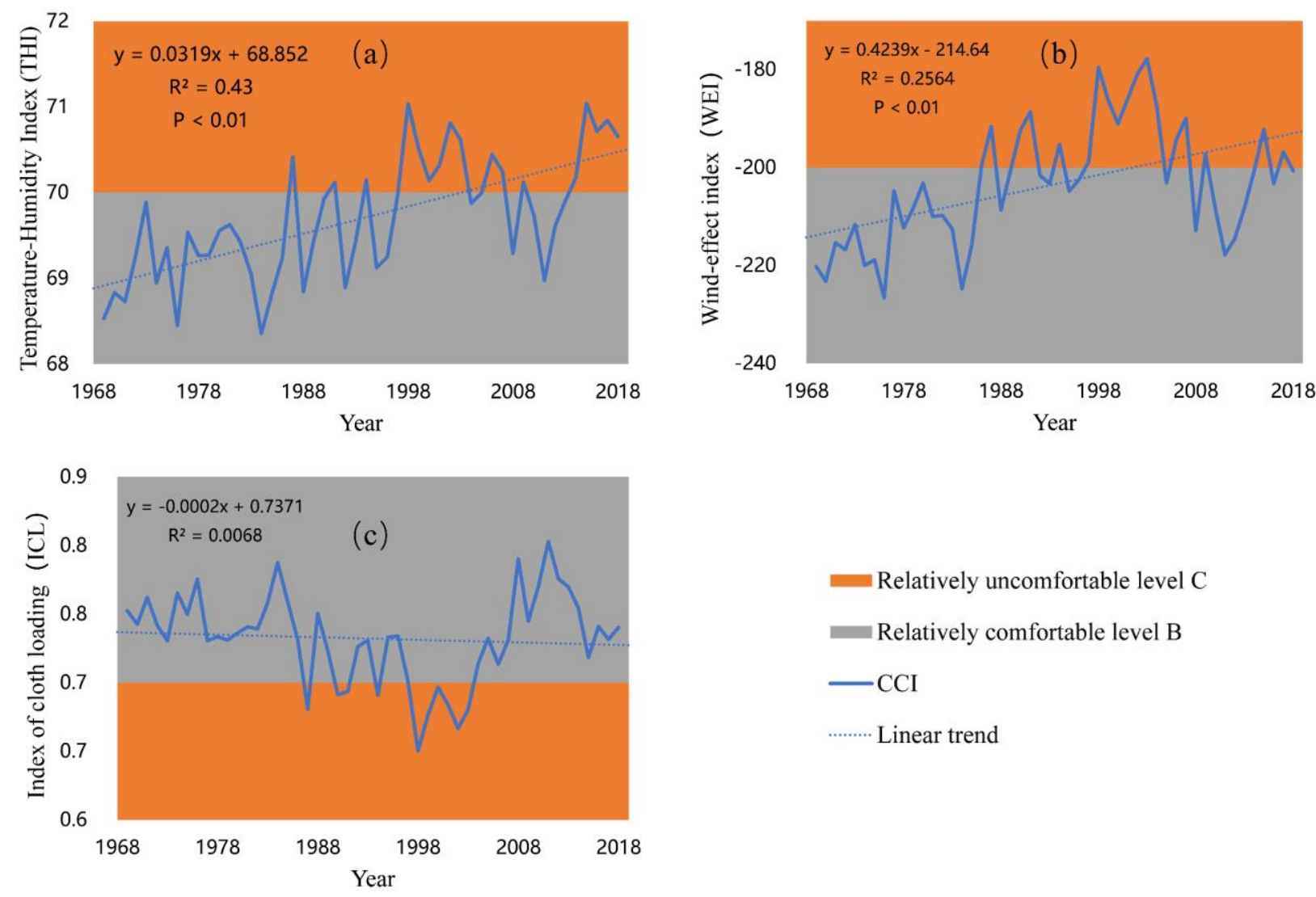

Figure 2: Interannual variations of comfort index from 1969 to 2018

The variation of averaged monthly uncomfortable periods in the last 50 years was given in Figure 3. In terms of heat and humidity, the relatively uncomfortable or uncomfortable periods of Guangdong lasted from May till October, connected with the high temperature and rich moistness of the late spring and entire summer. THI showed a gentle-slope parabolic curve with a minimum value of 56 (refreshing) in January, and a peak value of 80 (extremely muggy) in July (Fig. 3a). Guangdong was in relatively comfortable or comfortable level throughout the whole year except July and August in the perspective of wind. WEI exhibited a clearly inverted V shape with a minimum value of -403 (cool wind) in January, which increased with the gradually strengthened wind and growing temperature and peaked at -38 (slightly hot wind) in July (Fig. 3b). ICL is inversely correlated with temperature, higher $I C L$ represents more clothes loading. The $I C L$ in Guangdong displayed a V shape 
with a maximum value at 1.36 in January, when people had to wear winter clothes. As temperature grew, $I C L$ reduced every month and reached a minimum value at 0.26 in July, tropical single-layer clothes needed under such climatic condition. The relative uncomfortable and uncomfortable periods concerning clothing spanned from May through to September (Fig. 3c).

As for the monthly comfort levels (Figure 3), July and August held the least comfortable or relatively comfortable days, followed by June and September. People feel more comfortable in October than in May and April. November to the following March retained higher comfortability, under all climatic perspectives. Annually, the average number of days at the relatively comfortable or comfortable level of THI was around 135 days, accounting for $37 \%$ of the entire year, much lower than that of $W E I$ and $I C L$, which were 307 and 211 days respectively, about $84 \%$ and $58 \%$ of the year. The heat and humidity in summer was the main source of the climatic uncomfortable in Guangdong province.
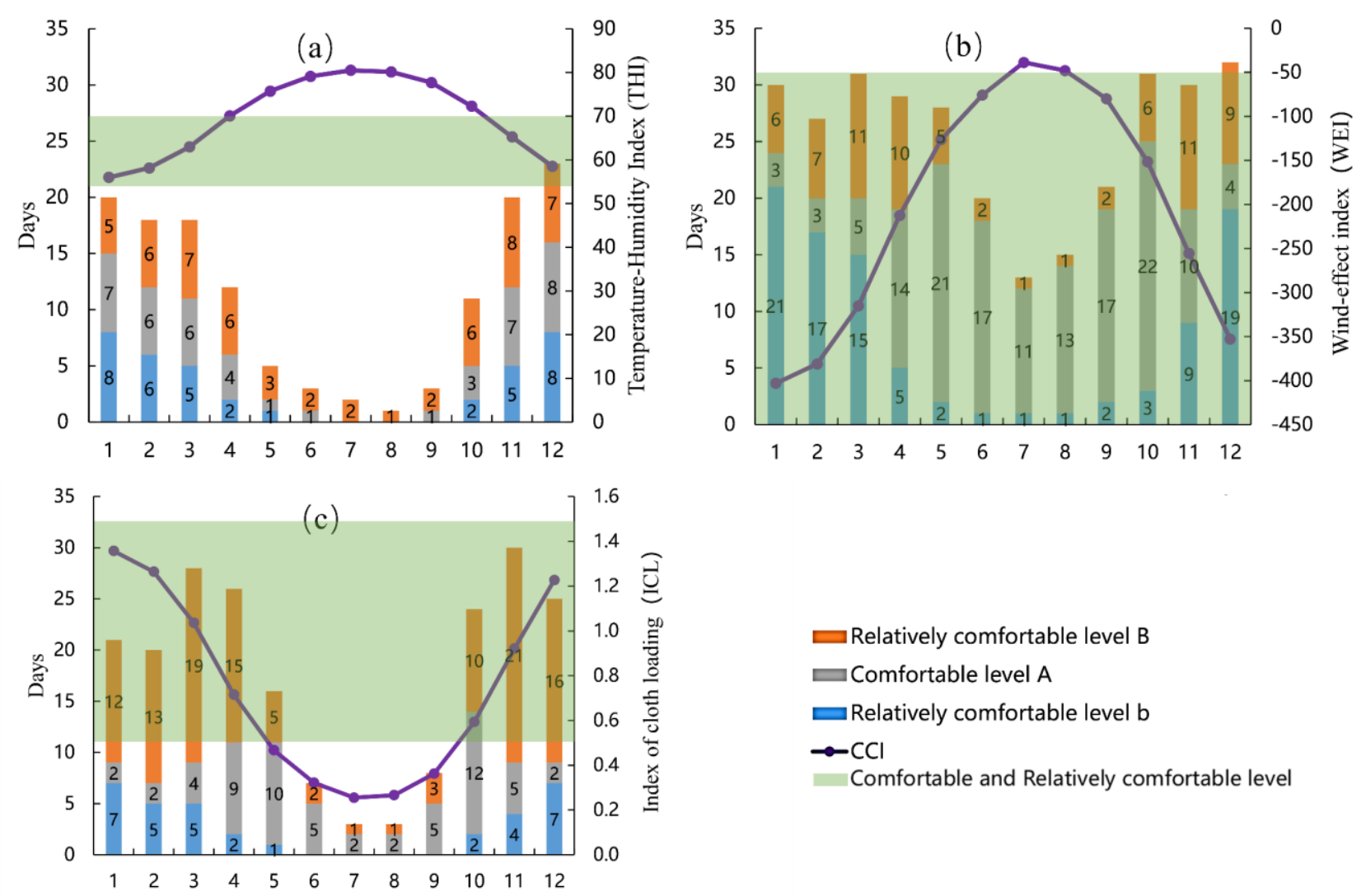

Fig. 3 Monthly variation of comfort index and period of different grades from 1969 to 2018 
According to the annual average number of days at different comfort levels in the last 50 years (Table 2), the extremely muggy and muggy days judged by $T H I$ were the highest, reached 107 and $71 \mathrm{~d}$ respectively. On the contrary, the extremely cold and cold days connected to $T H I$ were the least, showing $2 \mathrm{~d}$ and $5 \mathrm{~d}$ respectively. When referring to the wind impact, the relatively uncomfortable (slightly hot wind) days was the most common according to WEI, exhibiting $135 \mathrm{~d}$. And when it comes to the clothing loading, there were around 110 ICL comfortable days and 77 ICL uncomfortable or extremely uncomfortable days.

We examined the number of days of different comfortable level at the $10 \mathrm{yr}$ slice to investigate the temporal climate trend. In view of the temporal variation of the comfortable level (Figure 2), the extremely muggy days stemmed from $T H I$ exhibited a significant rising trend with $2.83 \mathrm{~d} / 10$ a growing rate, while days at all the other levels showed significant falling trend. For WEI and ICL, the number of days at the relatively cool level presented a decreasing trend, while the relatively hot days were on the contrary presenting a distinct growing trend. All the indexes indicated the warming inclination of Guangdong Province, aggravating the deterioration of climate comfortability.

Table 2: Variation characteristics of phased comfort index from 1969 to 2018 (day/year)

\begin{tabular}{|c|c|c|c|c|c|c|c|c|c|c|}
\hline & Period & $\mathrm{e}$ & d & $\mathrm{c}$ & $\mathrm{b}$ & A & B & $\mathrm{C}$ & $\mathrm{D}$ & $\mathrm{E}$ \\
\hline \multirow{8}{*}{ THI } & $\begin{array}{l}\text { Human } \\
\text { feeling }\end{array}$ & Ecold & Cold & Rcold & Cchilly & Cool & Warm & Rhot & Muggy & EMuggy \\
\hline & 1969-1978 & 3 & 5 & 40 & 39 & 41 & 43 & 49 & 97 & 2 \\
\hline & 1979-1988 & 2 & 6 & 38 & 41 & 42 & 44 & 51 & 87 & 59 \\
\hline & 1989-1998 & 2 & 4 & 24 & 27 & 37 & 44 & 45 & 62 & 125 \\
\hline & 1999-2008 & 1 & 3 & 18 & 21 & 31 & 42 & 46 & 53 & 152 \\
\hline & 2009-2018 & 2 & 4 & 20 & 24 & 33 & 39 & 42 & 56 & 149 \\
\hline & Averaged & 2 & 5 & 28 & 30 & 37 & 42 & 47 & 71 & 107 \\
\hline & TR & -0.04 & $-0.06^{*}$ & $-0.58 * *$ & $-0.49 * *$ & $-0.26 * *$ & $-0.12 * *$ & $-0.18^{*}$ & $-1.12 *$ & $2.83 * *$ \\
\hline \multirow{7}{*}{ WEI } & $\begin{array}{l}\text { Human } \\
\text { feeling }\end{array}$ & EcoldW & ColdW & ScoldW & CoolW & CW & WarmW & ShotW & hotW & EhotW \\
\hline & 1969-1978 & 0 & 2 & 10 & 93 & 67 & 130 & 64 & 0 & 0 \\
\hline & 1979-1988 & 0 & 2 & 8 & 91 & 65 & 130 & 67 & 1 & 0 \\
\hline & 1989-1998 & 0 & 1 & 6 & 81 & 68 & 141 & 67 & 1 & 0 \\
\hline & 1999-2008 & 0 & 1 & 6 & 78 & 70 & 142 & 71 & 1 & 0 \\
\hline & 2009-2018 & 0 & 1 & 7 & 91 & 66 & 132 & 70 & 2 & 0 \\
\hline & Averaged & 0 & 1 & 7 & 87 & 67 & 135 & 68 & 1 & 0 \\
\hline
\end{tabular}




\begin{tabular}{|c|c|c|c|c|c|c|c|c|c|c|}
\hline & TR & 0 & -0.01 & -0.07 & $-0.17 *$ & 0.01 & 0.18 & 0.14 & 0.03 & 0 \\
\hline \multirow{8}{*}{ ICL } & $\begin{array}{l}\text { Human } \\
\text { wear }\end{array}$ & $\begin{array}{l}\text { Down- } \\
\text { filled/fur } \\
\text { clothes }\end{array}$ & $\begin{array}{l}\text { Casual } \\
\text { clothes } \\
\text { /coats }\end{array}$ & $\begin{array}{l}\text { Winter } \\
\text { clothes }\end{array}$ & $\begin{array}{c}\text { S/A } \\
\text { clothes }\end{array}$ & Skirts & $\begin{array}{c}\text { Light } \\
\text { summer } \\
\text { clothes }\end{array}$ & $\begin{array}{l}\text { Polo } \\
\text { shirts }\end{array}$ & $\begin{array}{l}\text { Tropical } \\
\text { clothes }\end{array}$ & $\begin{array}{l}\text { Light } \\
\text { tropical } \\
\text { clothes }\end{array}$ \\
\hline & 1969-1978 & 0 & 12 & 27 & 29 & 108 & 50 & 84 & 46 & 13 \\
\hline & 1979-1988 & 0 & 11 & 25 & 30 & 109 & 49 & 78 & 52 & 13 \\
\hline & 1989-1998 & 0 & 9 & 22 & 25 & 111 & 50 & 77 & 56 & 15 \\
\hline & 1999-2008 & 0 & 9 & 21 & 23 & 112 & 49 & 82 & 59 & 13 \\
\hline & 2009-2018 & 0 & 10 & 24 & 27 & 110 & 52 & 77 & 63 & 7 \\
\hline & Averaged & 0 & 10 & 24 & 27 & 110 & 50 & 79 & 55 & 12 \\
\hline & TR & 0 & $-0.03 *$ & -0.09 & $-0.11 *$ & $0.05^{*}$ & 0.06 & -0.06 & 0.39 & $-0.12 * *$ \\
\hline
\end{tabular}

Notes: the bold $\mathbf{E} / \mathbf{R} / \mathbf{C} / \mathbf{W} / \mathbf{S}$ refers to extremely/relatively/comfort/wind/slightly respectively. TR = inclination rate. Blue represents decrease; orange indicates increase. * refers to passing 0.05 significance test. ** refers to passing 0.01 significance test.

\subsection{CCI variations along time}

Affected by the regional climate changes, the comprehensive CCI of Guangdong Province has continuously decreased. According to the variation characteristics of CCI in the previous 50 years (Figure 4-a), three stages were clearly divided. From 1968 to 1990, the climate comfortability was steadily maintained at relatively comfortable level, while an obvious decline was witnessed in 1991, and the CCI was kept at the border of the relative comfortable. Since 1998, the climate comfortability degraded continuously and stepped into relatively uncomfortable stage.

The monthly curve of comfort degree showed an obvious "V" type change (Figure 4-b), with CCL floating between 2.9-3.6 (the uncomfortable level) in a trough period from June to August, during which only 2-4 comfortable or relatively comfortable days were identified from each month. The comfortable days were mainly found from October to the next April, of which the comfort degrees of January, March, and December were the highest. 

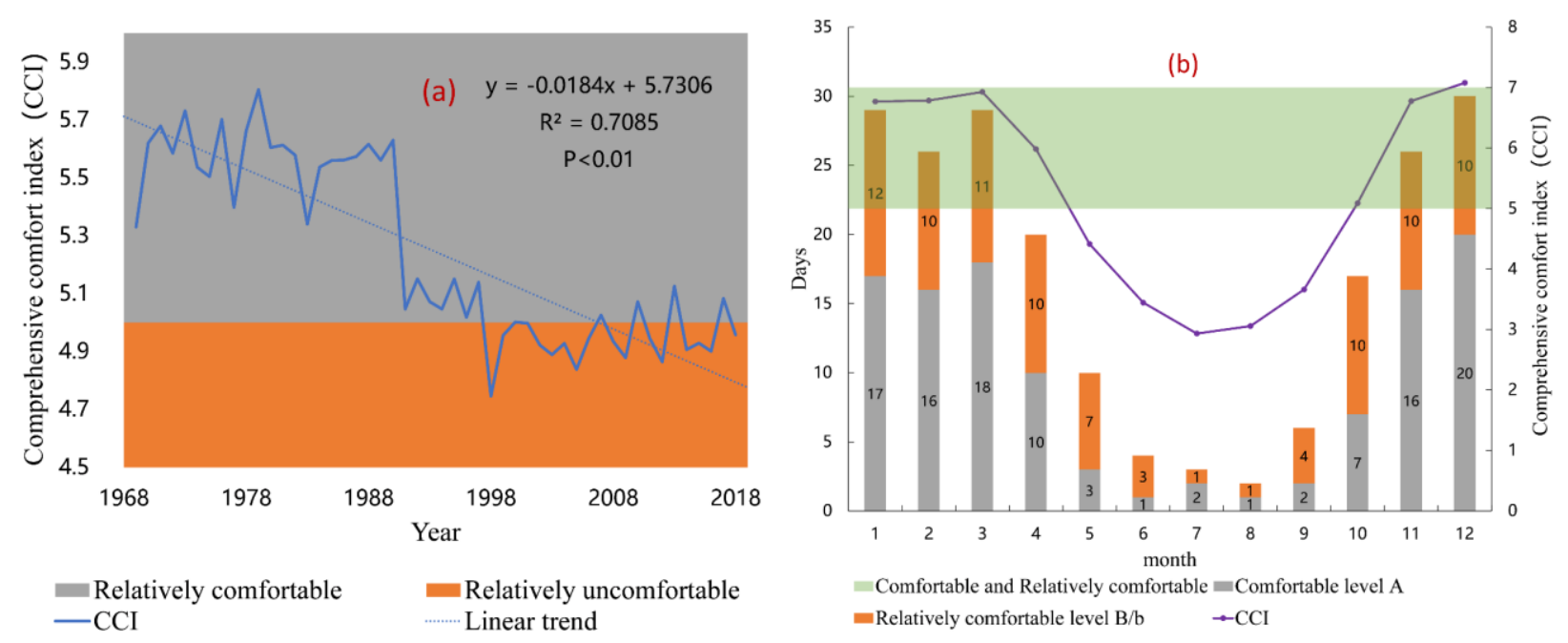

Figure 4: Interannual variations of CCI (a) and monthly variation of CCI and comfortable duration of different grades (b)

In terms of the variation tendency of the CCI (relatively) comfortable and (relatively) uncomfortable days (Table 3), the comfortable and relatively comfortable days prominently reduced at a rate of $1.06 \mathrm{~d} / 10$ a and $0.28 \mathrm{~d} / 10 \mathrm{a}$. Meanwhile, the uncomfortable and Table 3 the Variation characteristics of comfort period of comprehensive index between different years from 1969-2018

\begin{tabular}{ccccc}
\hline Grading & Comfortable & $\begin{array}{c}\text { Relatively } \\
\text { comfortable }\end{array}$ & $\begin{array}{c}\text { Relatively } \\
\text { uncomfortable }\end{array}$ & $\begin{array}{c}\text { Uncomfo } \\
\text { rtable }\end{array}$ \\
\hline $1969-1978$ & 120 & 90 & 112 & 43 \\
$1979-1988$ & 123 & 90 & 101 & 49 \\
$1989-1998$ & 98 & 81 & 119 & 64 \\
$1999-2008$ & 83 & 83 & 128 & 71 \\
$2009-2018$ & 86 & 80 & 128 & 70 \\
Averaged & 102 & 85 & 117 & 59 \\
TR & $-1.06^{* *}$ & $-0.28^{* *}$ & $0.64^{* *}$ & $0.73^{* *}$ \\
\hline Notes: Similar to Tab.2 & & &
\end{tabular}
significantly increased with the rate of $0.73 \mathrm{~d} / 10$ a and $0.64 \mathrm{~d} / 10$ a (Table 3). Combined with Table 2, in which the number of days at the relatively cold level decreased, and the number of days at the relatively hot level increased, suggesting that the increased number of days at the uncomfortable level was mainly led by the higher number of days at the relatively hot (uncomfortable) level.

In accordance with the number of days at the uncomfortable level in summer and its spatial distribution characteristics (Figure 5-a), the large numbers of days at the uncomfortable level were mainly distributed in Zhanjiang, Foshan, Zhongshan, Shantou, and the surrounding regions, of which the average numbers of days at the uncomfortable level in summer of these cities reached 47-51 days. The average minimum number of days at the uncomfortable level in summer was distributed in Heyuan and other regions in the northeast, and the annual average number of days at the 
uncomfortable level was 37 . The changing trend of the number of annual uncomfortable days and its spatial distribution characteristics were detected and the result was provided in Figure 5-b. In general, the number of the uncomfortable days increased all over the province. Spatially, the northern and eastern Guangdong exhibited the large increase rate, while the rest part of the region showed relatively slower growing in the uncomfortable days. As a result, with the discomfort degree rose as a whole in all of the regions, the spatial heterogeneity gradually narrowed along with time. The southeastern province displayed both the high discomfort degree and high deterioration rate, especially the marine region of Shantou, Jieyang and Shanwei, confronting with more severe heat threaten and environmental risk.
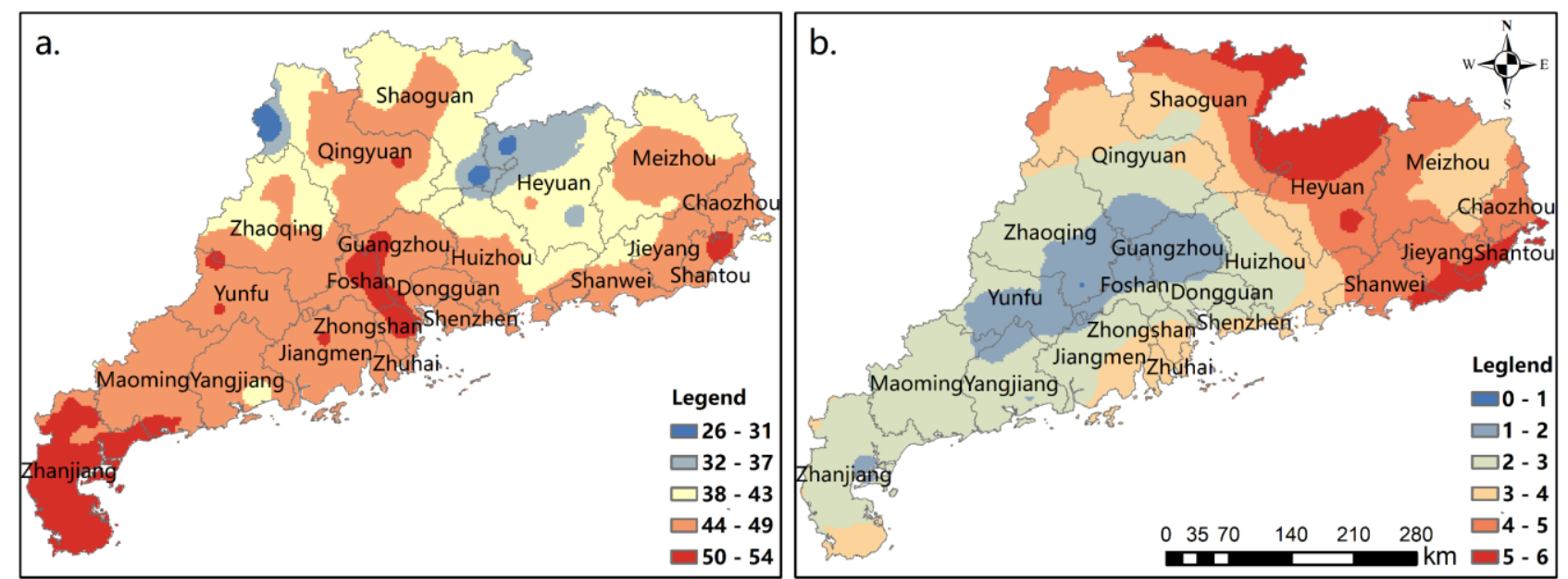

Figure 5: Distribution of the annual average discomfort days and its variation trend from 1969-2018

Notes: The spatial distribution of the number of days at the uncomfortable level is shown in a. The spatial distribution of the variation tendency of uncomfortable days is provided in $b$.

\subsection{Population exposure to climate discomfort in summer}

On the basis of the long sequence of the uncomfortable level in summer and population distribution data, the population exposure to climate discomfort in summer were explored, and its temporal-spatial change pattern were shown in Fig. 6. The high population exposure was mainly concentrated in the Pearl River Delta (PRD) and eastern Guangdong. The core cities of PRD, including Guangzhou and Shenzhen served as the high-exposure center, and at the same time exhibited the largest growth from 1990 to 2015, especially in the midst of the city. In 2010, the population exposure of Guangzhou firstly achieved 24 thousand people, with the area of exposure 
covering $28 \mathrm{~km}^{2}$, while Shenzhen surmounted 24,000 people exposure to discomfort climate with a $32 \mathrm{~km}^{2}$ coverage in 2015 . In provincial level, the population exposure and its coverage area were continuously expanding from 1990 to 2015. In 1990, the area of population exposure of higher than 3,000 people covered $255 \mathrm{~km}^{2}$ in total, which stretched to $1,724 \mathrm{~km}^{2}, 2,282 \mathrm{~km}^{2}$, and 3,408 $\mathrm{km}^{2}$, in 2000, 2010, and 2015 respectively.
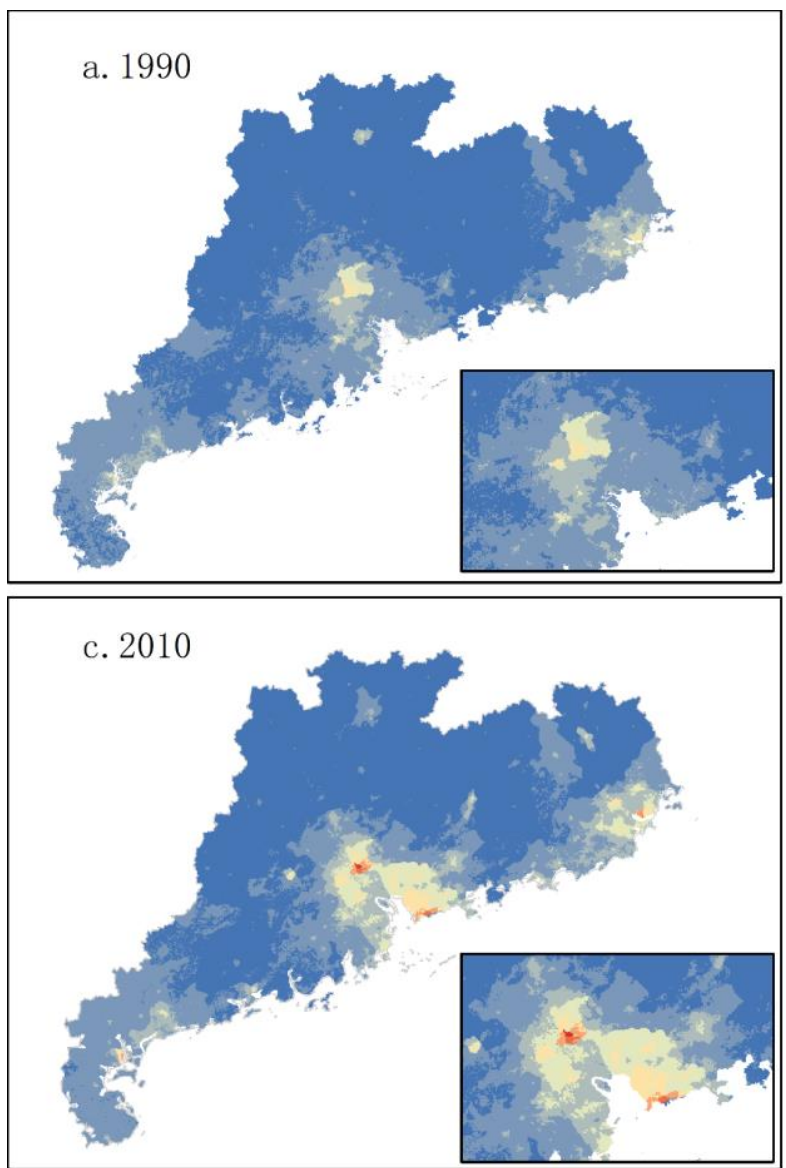

population exposure/person

\begin{tabular}{l}
$0-200 \square 201-600 \square 601-1,500 \square 1,501-3,000 \square 3,001-6,000$ \\
\hline
\end{tabular}
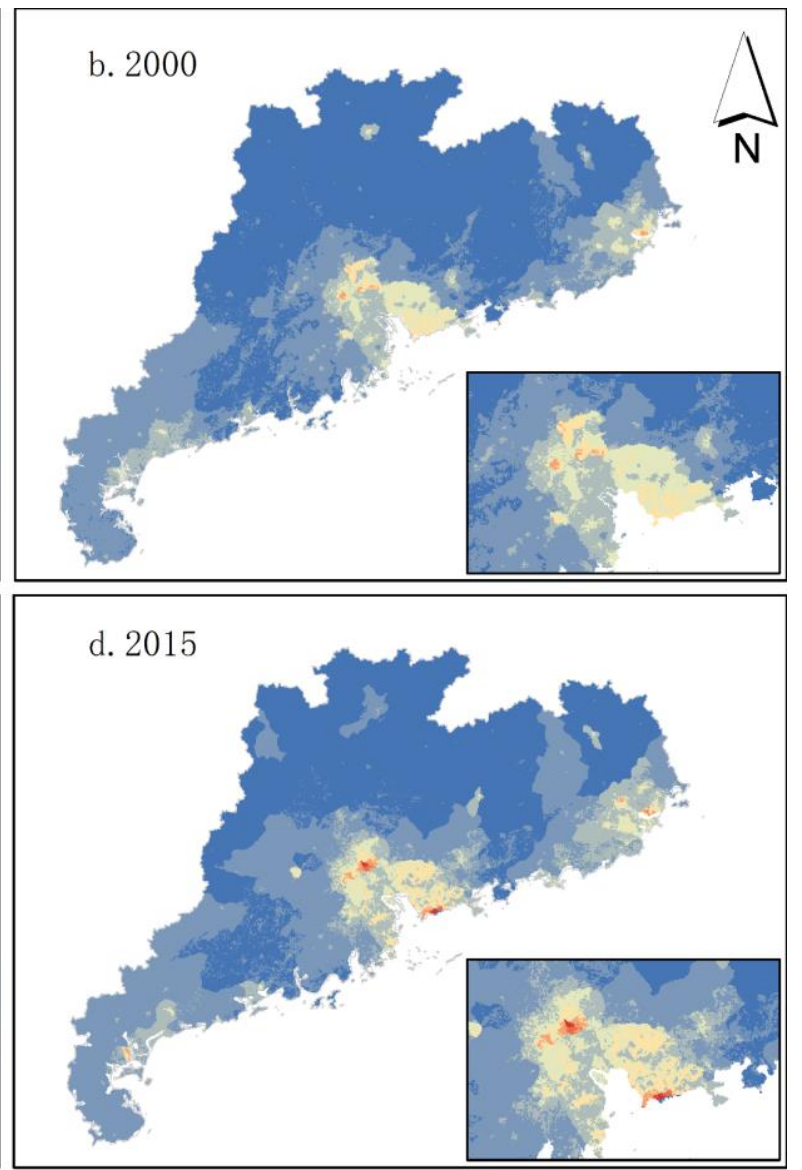

$6,001-12,000$

$12,001-24,000$

$24,001-32,000$

Figure 6: Spatial distribution of population exposure to uncomfortable climate in summer of 1990, 2000, 2010, and 2015

High population exposure was mainly observed in the Pearl River Delta. The population exposure to climate discomfort overall significantly increased in all prefecture-level cities (Fig. 7). Being the prefecture-level city with the highest population exposure to climate discomfort and the highest rate increase in Guangdong province. the increased rate of population exposure in Shenzhen was 2.94 million people/10 a and reached 9.29 million people in 2015 . The rise rate of population 
exposure in Dongguan, Foshan, and Shantou were also high, around 1.7 million people/10 a, 1.19 million people/10 a, and 0.83 million people/10 a, respectively, and exceeded 5 million people in 2015 in the three citis. Because of the low population growth rate, the increase of population exposure to climate discomfort was relatively slow in Zhuhai, Chaozhou, Jieyang, Zhongshan, and other cities.

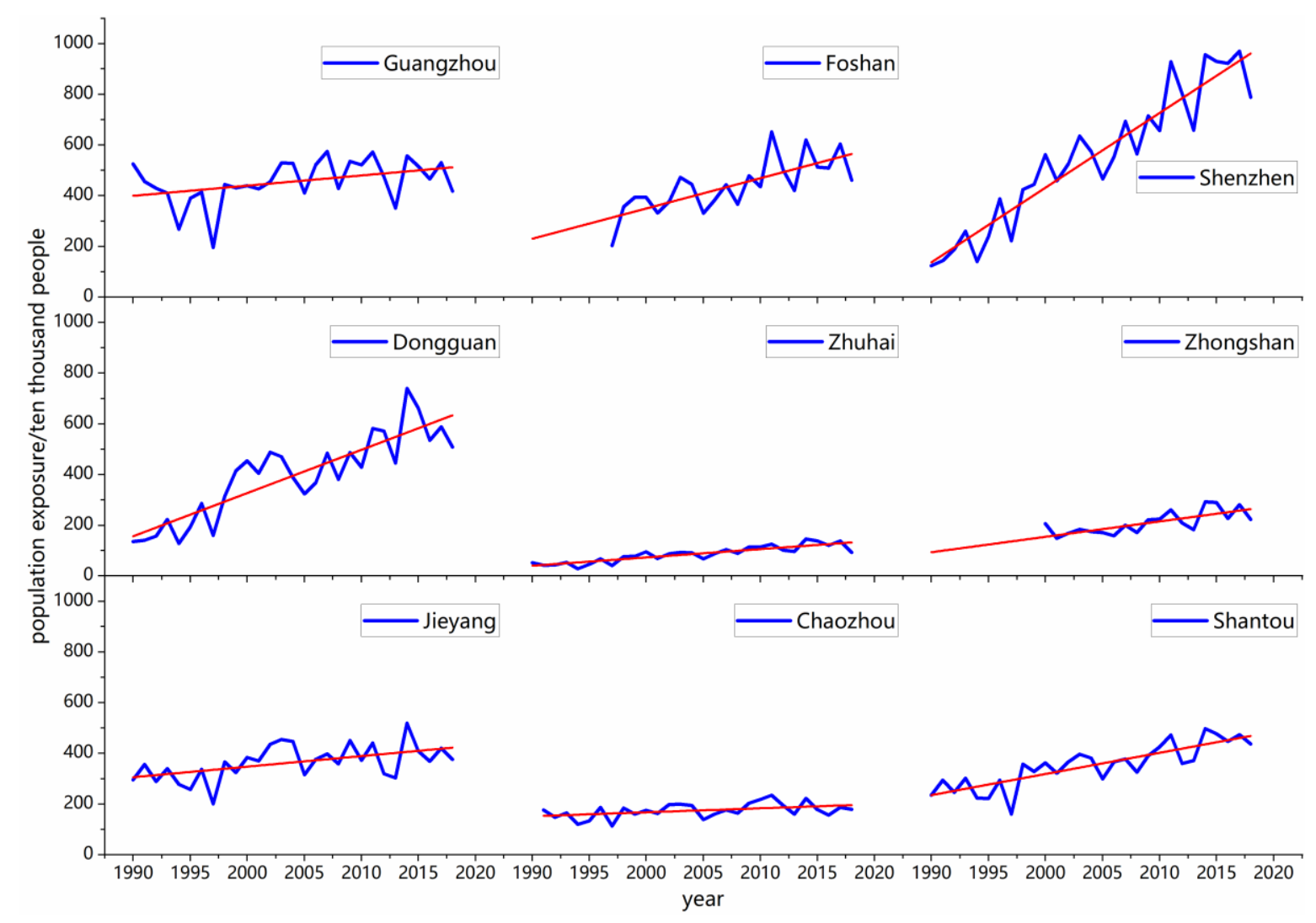

Figure 7: Distribution of annual population exposure to uncomfortable climate in summer in prefecture-level cities Notes: Solid red line represents variation tendency of population exposure, reaching a significance level of 0.05 .

\section{Discussions}

Previous studies have revealed that the deterioration of CCI in south China has been more rapid than the national average level in the context of global climate changes and urbanization development. Influenced by the changes in temperature, wind speed, relative humidity, and other climatic factors, the annual average WEI in south China has substantially increased(Wang et al., 2012). The climate sensitivity of northeast and south China is higher than that of other regions; hot days in south China throughout the year have increased substantially, and the possibility of future increase tends to be larger than that of nearly all other regions under various climate scenario(Jin et al., 2019). The results 
of this study are essentially consistent with those of previous research regarding CCI changes towards the relatively hot level and the rapid deterioration.

The spatial distribution of annual average THI and CCI are clearly affected by latitude and altitude, of which Guangxi, Guangdong, and Hainan have shown the highest discomfort degree connected to high temperature and humidity(Deng and Bao, 2020). The discomfort degree of the Pearl River Delta far exceeded that of the Yangtze River Delta and the Beijing-Tianjin-Tangshan region because many areas in the Pearl River Delta are at the uncomfortable level, and most areas in the Yangtze River Delta and the Beijing-Tianjin-Tangshan region are at the relatively uncomfortable or relatively comfortable levels in the last decades. Our study indicated that $47 \%$ of days were at the uncomfortable level in summer in Guangdong Province during the past 50 years, demonstrating the increasing local heat risk and threaten.

In addition, according to the annual uncomfortable duration and the spatial variation tendency in summer in the last 50 years, the Pearl River Delta, Zhanjiang, and the surrounding regions presented the highest climate discomfort degree, and CCI deterioration rate of these regions was relatively lower than that the other regions. Hence, the regional heterogeneity of discomfort degree in summer in Guangdong Province tend to be narrowed, but the comprehensive discomfort degree would prominently grow.

Long-term discomfort weather or climate presents certain accumulation effect, and servers as one of the important influencing factors related to disease occurrence and social-economic development(Cetin, 2020; Hayes et al., 2018; Stechemesser et al., 2021). For example, high temperatures and high humidity exerting critical impacts on respiratory and cardiovascular diseases according to medical reports and research(Im et al., n.d.; Lin et al., 2017; Luan et al., 2017). A case study regarding to the healthy impact of temperature in Guangzhou and Zhuhai suggested that high temperatures lead to a lowering of life expectancy of residents(Li et al., 2015). Climate warming in Guangzhou in the future will further reduce residents' life expectancy, excluding the changes of future populations and their adaptive capacities, while improvements of residents' regulatory and adaptive capacities could resist the influence of climate deterioration to a significant extent in the future (Liu et al., 2018). Studies of population health in the Greater Bay Area revealed that the daily average 
temperature threshold could increase the risk of death for residents; for example, heatwaves seriously degrade residents' life quality, leading to a worsening of diseases or even result in death. Therefore, researching on the occurrence and development of climate discomfort and regional diseases is of high significance. To improve the health conditions and climate comfortable level of regional residents, corresponding measures must be taken as soon as possible to halt the momentum of the rapid deterioration of CCI, particularly in summer and in areas with increased population exposure, such as Pearl River Delta, and eastern Guangdong province. In this study, the temporal-spatial changes of population exposure to climate discomfort in summer in Guangdong Province were preliminarily investigated to improve understanding of regional CCI deterioration trend, expand the knowledge of the climate impact on human, and provide scientific basis for the responding countermeasures.

\section{Conclusions}

In this paper, the temporal-spatial distribution characteristics of Climate Comfort Index (CCI) and the population exposure under the background of climate variations and population aggregation were explored on the basis of daily meteorological records monitored from 86 ground station from 1969 to 2018, and population archive of Guangdong Province since 1990. The results clearly showed that:

(1) the comfortability of climate was on decreasing trend in Guangdong Province in the last 50 years, due to the growing tendency of the heat and humidity. Temperature-humidity index (THI), wind effect inedx (WEI), and climate comfortable index (CCI) prominently increased, while index of clothes loading (ICL) constantly decreased. Relatively hot days showed significant growth, resulting in the rise of the uncomfortable and relatively uncomfortable days, with a rate of $0.73 \mathrm{~d} / 10$ a and $0.64 \mathrm{~d} / 10$ a, respectively.

(2) seasonal variation of CCI indicated that summer was the most uncomfortable season, with $47 \%$ of days at the uncomfortable level and only four days at the comfortable level. The comfortability in autumn was lower than that of Spring, while Winter was the most comfortable season.

(3) For the changes of population exposure to climate discomfort in summer, the high 
population exposure was mainly concentrated in the Pearl River Delta and Eastern Guangdong, and both the covering area and population exposure increased. In Guangzhou and Shenzhen, the population exposure prominently grew in 2010 and 2015, reaching 2,4000 people $/ \mathrm{km}^{2}$. The prefecture-level cities with high population exposure to climate discomfort in summer witnessed a significant increase. Specifically, Shenzhen, Dongguan, and Foshan presented a growth rate that exceeded 1 million people/10 a.

\section{Acknowledgments}

This research is supported by the Guangdong Province Universities and Colleges Pearl River Scholar Funded Scheme (2019), Natural Science Foundation of Guangdong Province (2020A1515011065) and Key Special Project for Introduced Talents Team of Southern Marine Science and Engineering Guangdong Laboratory (Guangzhou) (GML2019ZD0301). 
Aminipouri, M., Rayner, D., Lindberg, F., Thorsson, S., Knudby, A.J., Zickfeld, K., Middel, A., Krayenhoff, E.S., 2019. Urban tree planting to maintain outdoor thermal comfort under climate change: The case of Vancouver's local climate zones. Building and Environment 158, 226-236. https://doi.org/10.1016/j.buildenv.2019.05.022

Barbosa, R., Vicente, R., Santos, R., 2015. Climate change and thermal comfort in Southern Europe housing: A case study from Lisbon. Building and Environment 92, 440-451. https://doi.org/10.1016/j.buildenv.2015.05.019

Batibeniz, F., Ashfaq, M., Diffenbaugh, N.S., Key, K., Evans, K.J., Turuncoglu, U.U., Önol, B., 2020. Doubling of U.S. Population Exposure to Climate Extremes by 2050. Earth's Future 8, e2019EF001421. https://doi.org/10.1029/2019EF001421

Blazejczyk, K., Epstein, Y., Jendritzky, G., Staiger, H., Tinz, B., 2012. Comparison of UTCI to selected thermal indices. Int J Biometeorol 56, 515-535. https://doi.org/10.1007/s00484-011-04532

Cai, B., Zhou, M., 2012. A comparative evaluation of climate comfort between Myrica rubra community and Cunninghamia lanceolata community. Journal of Inner Mongolia Agricultural University (Natural Science Edition) 33, 45-51.

Cetin, M., 2020. Climate comfort depending on different altitudes and land use in the urban areas in Kahramanmaras City. Air Qual Atmos Health 13, 991-999. https://doi.org/10.1007/s11869-020-00858-y

Chen, J., Li, X., Zhang, M., 2005. Simulating the impacts of climate variation and land-cover changes on basin hydrology: A case study of the Suomo basin. Sci. China Ser. D-Earth Sci. 48, 15011509. https://doi.org/10.1360/03yd0269

Cheung, C.S.C., Hart, M.A., 2014. Climate change and thermal comfort in Hong Kong. Int J Biometeorol 58, 137-148. https://doi.org/10.1007/s00484-012-0608-9

De Freitas, C.R., 1979. Human climates of Northern China. Atmospheric Environment (1967) 13, 7177. https://doi.org/10.1016/0004-6981(79)90246-4

Deng, L., Bao, J., 2020. Spatial distribution of summer comfortable climate and winter comfortable climate in China and their differences. Geograhpical research 39, 41-52.

Dino, I.G., Meral Akgül, C., 2019. Impact of climate change on the existing residential building stock in Turkey: An analysis on energy use, greenhouse gas emissions and occupant comfort. Renewable Energy 141, 828-846. https://doi.org/10.1016/j.renene.2019.03.150

Feng, L., Liu, Y., Feng, Z., Yang, S., 2021. Analysing the spatiotemporal characteristics of climate comfort in China based on 2005-2018 MODIS data. Theor Appl Climatol 143, 1235-1249. https://doi.org/10.1007/s00704-020-03516-6

Fischer, E.M., Sippel, S., Knutti, R., 2021. Increasing probability of record-shattering climate extremes. Nat. Clim. Chang. 11, 689-695. https://doi.org/10.1038/s41558-021-01092-9

Forzieri, G., Bianchi, A., Silva, F.B. e, Marin Herrera, M.A., Leblois, A., Lavalle, C., Aerts, J.C.J.H., Feyen, L., 2018. Escalating impacts of climate extremes on critical infrastructures in Europe. Global Environmental Change 48, 97-107. https://doi.org/10.1016/j.gloenvcha.2017.11.007

Hayes, K., Blashki, G., Wiseman, J., Burke, S., Reifels, L., 2018. Climate change and mental health: risks, impacts and priority actions. International Journal of Mental Health Systems 12, 28. https://doi.org/10.1186/s13033-018-0210-6 
Hong, C., Zhang, Q., Zhang, Y., Davis, S.J., Tong, D., Zheng, Y., Liu, Z., Guan, D., He, K., Schellnhuber, H.J., 2019. Impacts of climate change on future air quality and human health in China. PNAS 116, 17193-17200. https://doi.org/10.1073/pnas.1812881116

Höppe, P., 1999. The physiological equivalent temperature - a universal index for the biometeorological assessment of the thermal environment. Int J Biometeorol 43, 71-75. https://doi.org/10.1007/s004840050118

Im, E.-S., Pal, J.S., Eltahir, E.A.B., n.d. Deadly heat waves projected in the densely populated agricultural regions of South Asia. Science Advances 3, e1603322. https://doi.org/10.1126/sciadv.1603322

Jin, A., Zhang, A., Zhao, X., 2019. Estimation of Climate Comfort in Eastern China in the Context of Climate. Acta Scientiarum Naturalium Universitatis Pekinensis 55, 165-174.

Ko, W.H., Schiavon, S., Zhang, H., Graham, L.T., Brager, G., Mauss, I., Lin, Y.-W., 2020. The impact of a view from a window on thermal comfort, emotion, and cognitive performance. Building and Environment 175, 106779. https://doi.org/10.1016/j.buildenv.2020.106779

Kramer, R., van Schijndel, J., Schellen, H., 2017. Dynamic setpoint control for museum indoor climate conditioning integrating collection and comfort requirements: Development and energy impact for Europe. Building and Environment 118, 14-31. https://doi.org/10.1016/j.buildenv.2017.03.028

$\mathrm{Li}, \mathrm{R} ., \mathrm{Chi}, \mathrm{X} ., 2014$. Thermal comfort and tourism climate changes in the Qinghai-Tibet Plateau in the last 50 years. Theor Appl Climatol 117, 613-624. https://doi.org/10.1007/s00704-0131027-5

Li, S., Wang, Z., Lai, C., Lin, G., 2020. Quantitative assessment of the relative impacts of climate change and human activity on flood susceptibility based on a cloud model. Journal of Hydrology 588, 125051. https://doi.org/10.1016/j.jhydrol.2020.125051

Li, Z., Xu, Y., Lin, G., Liu, T., Lin, H., Xiao, J., Zeng, W., Li, X., Ma, W., 2015. Impact of air temperature on years of life lost among residents in Guangzhou and Zhuhai: a time-series study. Chinese Journal of Epidemiology 36, 720-724. https://doi.org/10.3760/cma.j.issn.02546450.2015.07.012

Lin, Z., Meng, X., Chen, R., Huang, G., Ma, X., Chen, J., Huang, Min, Huang, Meirong, Gui, Y., Chu, C., Liu, F., Kan, H., 2017. Ambient air pollution, temperature and kawasaki disease in Shanghai, China. Chemosphere 186, 817-822. https://doi.org/10.1016/j.chemosphere.2017.08.054

Liu, T., Xiao, J., Zeng, W., Li, X., Li, Z., Lin, H., Du, Y., Xu, X., Ma, W., 2018. Investigation on the Heat Effect of Climate Change on Years of Life Lost in Guangzhou. Journal of Environmental Hygiene 8, 393-398.

Luan, G., Yin, P., Li, T., Wang, L., Zhou, M., 2017. The years of life lost on cardiovascular disease attributable to ambient temperature in China. Sci Rep 7, 13531. https://doi.org/10.1038/s41598-017-13225-2

Ma, L., Sun, G., 2009. Evaluation of climate comfort index for tourism hot-spot cities in west China. Arid Land Geography 32, 791-797.

Matzarakis, A., 2013. Transferring Climate Information for Application and Planning: The ClimateTourism/Transfer-Information-Scheme, in: Helmis, C.G., Nastos, P.T. (Eds.), Advances in Meteorology, Climatology and Atmospheric Physics, Springer Atmospheric Sciences. Springer, 
Berlin, Heidelberg, pp. 591-597. https://doi.org/10.1007/978-3-642-29172-2_84

Noome, K., Fitchett, J.M., 2019. An assessment of the climatic suitability of Afriski Mountain Resort for outdoor tourism using the Tourism Climate Index (TCl). J. Mt. Sci. 16, 2453-2469. https://doi.org/10.1007/s11629-019-5725-z

Odnoletkova, N., Patzek, T.W., 2021. Data-Driven Analysis of Climate Change in Saudi Arabia: Trends in Temperature Extremes and Human Comfort Indicators. Journal of Applied Meteorology and Climatology 60, 1055-1070. https://doi.org/10.1175/JAMC-D-20-0273.1

Poupkou, A., Nastos, P., Melas, D., Zerefos, C., 2011. Climatology of Discomfort Index and Air Quality Index in a Large Urban Mediterranean Agglomeration. Water Air Soil Pollut 222, 163-183. https://doi.org/10.1007/s11270-011-0814-9

Rong, Y., Zhang, X., He, Q., 2017. Study and Analysis of Meteorological Effect on Shanghai Sheshan National Tourist Resorts in Shanghai. Journal of Geoscience and Environment Protection 5, 11-22. https://doi.org/10.4236/gep.2017.57002

Roshan, G., Mirkatouli, G., Shakoor, A., Mohammad-Nejad, V., 2010. Studying Wind Chill Index as a Climatic Index Effective on the Health of Athletes and Tourists Interested in Winter Sports. Asian J Sports Med 1, 108-116.

Scott, D., Rutty, M., Amelung, B., Tang, M., 2016. An Inter-Comparison of the Holiday Climate Index $(\mathrm{HCl})$ and the Tourism Climate Index $(\mathrm{TCl})$ in Europe. Atmosphere 7, 80. https://doi.org/10.3390/atmos7060080

Steadman, R.G., 1979. The Assessment of Sultriness. Part I: A Temperature-Humidity Index Based on Human Physiology and Clothing Science. Journal of Applied Meteorology and Climatology 18, 861-873. https://doi.org/10.1175/1520-0450(1979)018<0861:TAOSPI>2.0.CO;2

Stechemesser, A., Wenz, L., Kotz, M., Levermann, A., 2021. Strong increase of racist tweets outside of climate comfort zone in Europe. Environ. Res. Lett. 16, 114001. https://doi.org/10.1088/1748-9326/ac28b3

Summa, S., Tarabelli, L., Ulpiani, G., Di Perna, C., 2020. Impact of Climate Change on the Energy and Comfort Performance of nZEB: A Case Study in Italy. Climate 8, 125. https://doi.org/10.3390/cli8110125

Sun, G., Yu, Z., 2014. Relationship of climate comfort degree of cities near $30^{\circ} \mathrm{N}$ and $35^{\circ} \mathrm{N}$ with 3-step terrain of China. Arid Land Geography 37, 447-457.

Thiery, W., Lange, S., Rogelj, J., Schleussner, C.-F., Gudmundsson, L., Seneviratne, S.I., Andrijevic, M., Frieler, K., Emanuel, K., Geiger, T., Bresch, D.N., Zhao, F., Willner, S.N., Büchner, M., Volkholz, J., Bauer, N., Chang, J., Ciais, P., Dury, M., François, L., Grillakis, M., Gosling, S.N., Hanasaki, N., Hickler, T., Huber, V., Ito, A., Jägermeyr, J., Khabarov, N., Koutroulis, A., Liu, W., Lutz, W., Mengel, M., Müller, C., Ostberg, S., Reyer, C.P.O., Stacke, T., Wada, Y., 2021. Intergenerational inequities in exposure to climate extremes. Science 374, 158-160. https://doi.org/10.1126/science.abi7339

Wang, M., Zheng, S., Wang, S., Shang, K., 2012. The tendency of spatial-temporal changes of wind effect index in main capital cities in China from 1951 to 2008. Journal of arid land resources and environment 26, 64-70.

Wilson, O., 1967. Objective evaluation of wind chill index by records of frostbite in the Antarctica. Int J Biometeorol 11, 29-32. https://doi.org/10.1007/BF01424272 
Wu, F., Yang, X., Shen, Z., 2019. Regional and seasonal variations of outdoor thermal comfort in China from 1966 to 2016. Science of The Total Environment 665, 1003-1016. https://doi.org/10.1016/j.scitotenv.2019.02.190

Wu, F., Yang, X., Shen, Z., Yi, Z., 2020. Long-term trends and spatiotemporal variations of climate comfort in China during 1966-2016. Thermal Science 24, 2445-2453.

Wu, Y., Graw, K., Matzarakis, A., 2020. Comparison of Thermal Comfort between Sapporo and Tokyo-The Case of the Olympics 2020. Atmosphere 11, 444. https://doi.org/10.3390/atmos11050444

Yang, B., Yang, X., Leung, L.R., Zhong, S., Qian, Y., Zhao, C., Chen, F., Zhang, Y., Qi, J., 2019. Modeling the Impacts of Urbanization on Summer Thermal Comfort: The Role of Urban Land Use and Anthropogenic Heat. Journal of Geophysical Research: Atmospheres 124, 6681-6697. https://doi.org/10.1029/2018JD029829

Zeng, D., Wu, J., Mu, Y., Deng, M., Wei, Y., Sun, W., 2020. Spatial-Temporal Pattern Changes of UTCI in the China-Pakistan Economic Corridor in Recent 40 Years. Atmosphere 11, 858. https://doi.org/10.3390/atmos11080858

Zhang, X., Jiang, C., Sun, J., Zhou, M., 2018. Spatio-temporal variation and influencing factors of thermal comfort at different elevations. Journal of Applied Ecology 29, 2808-2818.

Zhao, J., Wang, S., 2021. Spatio-Temporal Evolution and Prediction of Tourism Comprehensive Climate Comfort in Henan Province, China. Atmosphere 12, 823. https://doi.org/10.3390/atmos12070823

Zhou, J.-Q., Huang, W., Zhu, Y., Li, M., Zhou, B.-T., 2018. Climate comfort distribution, change and projection in Yunnan province. Advances in Climate Change Research 14, 144. https://doi.org/10.12006/j.issn.1673-1719.2017.065 